\title{
A field study of the behavioral and physiological effects of varying amounts of shade for lactating cows at pasture
}

\author{
K. E. Schütz, ${ }^{*}$ N. R. Cox, $†$ and C. B. Tucker $\ddagger^{1}$ \\ *Innovative Farm Systems, Ruakura Research Centre, AgResearch Ltd., Private Bag 3123, Hamilton 3240, New Zealand \\ †Invermay Statistics Group, Invermay Research Centre, AgResearch Ltd., Puddle Alley, Private Bag 50034, Mosgiel, New Zealand \\ ‡Department of Animal Science, University of California, 1 Shields Ave, Davis 95616
}

\section{ABSTRACT}

Shade reduces the negative effects of heat load, but little is known about how much is required for efficient cooling in commercial settings. The effect of the amount of shade on 8 Holstein-Friesian herds was studied for 2 consecutive summers (mean temperature: $23^{\circ} \mathrm{C}$ ) on 6 commercial, pasture-based dairy farms. Farms varied in the amount of natural shade provided (range: 0 to $15.6 \mathrm{~m}^{2}$ shade/cow). Time spent in shade, near water, eating, ruminating, lying, and standing were recorded between 1000 and $1530 \mathrm{~h}$ in 31 shaded and 11 unshaded paddocks using 20-min instantaneous scan observations of 15 focal cows/herd. Respiration rate and panting score (0 to 4.5) was recorded for focal animals once per hour. The total numbers of cows in shade, near water, and with panting scores $\geq 2$ were recorded every $30 \mathrm{~min}$. Cows without shade spent $4 \%$ more time lying than cows with shade (standard error of the difference, SED $=1.9 \%$ ). A larger proportion of the herd had panting scores $\geq 2$ when no shade was available ( 6 vs. $2 \%$ of the herd, SED $=1.2 \%$ ), and respiration rates were higher by 8 breaths $/ \mathrm{min}$ in cows without shade $(\mathrm{SED}=4.7$ breaths/min). Under the conditions tested, the maximum proportion of the herd that was observed using the shade increased by $3.1 \%$ for every $1-\mathrm{m}^{2}$ increase in shade size [standard error $(\mathrm{SE})=1.51 \%$ ], and all cows were first seen simultaneously using shade when $2 \mathrm{~m}^{2} /$ cow was provided. For every $1-\mathrm{m}^{2}$ increase in shade, $0.3 \%$ fewer cows had panting score $\geq 2(\mathrm{SE}=0.12 \%)$. We observed no significant relationships between the amount of shade available and any other variables. Although additional work is required to make specific recommendations, these results indicate that providing more shade allowed a higher proportion of animals to use this resource and reduced respiratory signs of heat load.

Received October 28, 2013.

Accepted March 4, 2014.

${ }^{1}$ Corresponding author: cbtucker@ucdavis.edu
Key words: behavior, dairy cattle, physiology, shade amount

\section{INTRODUCTION}

Warm weather in summer may cause an increase in the heat load experienced by cattle and impair both animal welfare and production. Behavioral responses to high heat load include an increase in shade use (Tucker et al., 2008; Schütz et al., 2009, 2010) and time spent near water (Schütz et al., 2010; Legrand et al., 2011), decreased feed intake (Hahn, 1999; Ominski et al., 2002), and a reduction in lying time (Tucker et al., 2008; Schütz et al., 2010). Physiological responses to heat load include increases in respiration rate and body temperature (Ominski et al., 2002; Schütz et al., 2010). If behavioral and physiological mechanisms are insufficient to reduce heat load, this may lead to decreased milk production (Wheelock et al., 2010) and, in extreme cases, in mortality (Stull et al., 2008).

Shade is an important resource to cattle in summer. Cows will compete for shade (Schütz et al., 2010), and use of shade is positively related to solar radiation levels and warm weather (Kendall et al., 2006; Tucker et al., 2008; Schütz et al., 2009). Access to shade reduces respiration rate and body temperature (Kendall et al., 2007; Schütz et al., 2010, 2011) and we have previously shown that the cooling benefits of shade are greater if it blocks more solar radiation (Tucker et al., 2008) and if enough is provided for all cows to use it simultaneously (Schütz et al., 2010). For example, cows that had access to $9.6 \mathrm{~m}^{2}$ shade/cow spent more than twice as much time in the shade compared with cows that had access to $2.4 \mathrm{~m}^{2}$ shade/cow; in addition, respiration rates were lower and less aggressive behavior occurred when more shade was provided (Schütz et al., 2010). The findings indicate that shade may need to be large enough for all cows to use it at the same time, but the specific amount of shade needed per cow is unknown.

Recommendations in the literature range between 3.5 and $5.6 \mathrm{~m}^{2}$ shade/cow for dairy cattle (Buffington et al., 1983; Collier et al., 2006), but these recommendations are largely based on changes in production measures 
(milk production, weight gain), which are likely to occur when behavioral and physiological responses have failed to prevent an increase in heat load. For example, beef cattle with access to $>3.5 \mathrm{~m}^{2}$ of shade/animal had higher feed intake and lower respiration rates than animals with 1.5 or $2.5 \mathrm{~m}^{2}$ shade/animal, but did not have higher weight gain (Mader et al., 1997). In addition, all previous work has examined the effect of shade size in relatively small experimental groups. Large groups of cattle may utilize resources (e.g., shade, water, feed) in different ways than smaller groups because of differences in social dynamics. Ultimately, recommendations about the amount of shade per cow are needed at the commercial scale, thus the current work placed emphasis on on-farm conditions. In addition to limitations of experimental work, even less is known about shade provided by trees or shrubs in pasture-based systems, compared with shade structures. The aim of this study was to investigate how behavior and physiology change with amount of shade in a pasture-based, commercial dairy system in summer.

\section{MATERIALS AND METHODS}

\section{Farms and Animals}

All procedures involving animals were approved by the Ruakura Animal Ethics Committee as required under the New Zealand Animal Welfare Act 1999. Data collection was undertaken on 6 commercial dairy farms in New Zealand for 2 consecutive years from January until beginning of March (Southern Hemisphere summer). A total of 6 farms with 8 herds in the Waikato region $\left(38^{\circ} \mathrm{S}, 175^{\circ} \mathrm{E}\right)$ were utilized. Average herd size, age, and milk production in February, for both years combined, was 213 cows (range: 148 to 280 cows), 4.5 yr (range: 2 to $17 \mathrm{yr}$ ), and $14.5 \mathrm{~L} / \mathrm{d}$ (range: 10.4 to $19.8 \mathrm{~L} / \mathrm{d}$, based on herd bulk tank values for the month of February). Seventy-three percent of the herds were milked twice daily and $82 \%$ of herds were fed supplements (in paddock, separate paddock, or on feed pad before p.m. milking) in addition to grass.

On each farm, several paddocks were identified as suitable for observations, ranging from nonshaded paddocks $(\mathrm{n}=11)$ to those that varied in the amount of available natural shade $(\mathrm{n}=31)$. Observations were carried out on days when the herds were allocated to selected paddocks by the farmer following rotational grazing. Available shade in the shaded paddocks ranged between 0.89 and $15.6 \mathrm{~m}^{2}$ shade/cow at $1200 \mathrm{~h}$ [median shade size was $\left.3.8 \mathrm{~m}^{2} / \mathrm{cow} \pm 3.92(\mathrm{SD})\right]$. One or 2 water troughs (average height: $0.5 \mathrm{~m}$, diameter: $1.3 \mathrm{~m}$, circumference: $4.1 \mathrm{~m}$, a float controlling the water level) were available in each paddock.

\section{Estimation of Shade Size}

To estimate the shade amount available in each paddock, we used a software program that calculates the shade cast by a solid object at different times of the day depending on season and location (WebShade, Balmain, NSW, Australia). In each paddock, the number and location of all trees, hedges, and shrubs that could cast shade, as well as the number and location of all water troughs, was recorded using a walking wheel (Fuller, Montréal, Québec, Canada). The height and width of each tree was recorded using laser binoculars with an accuracy of $\pm 1 \mathrm{~m}$ and $0.1 \mathrm{~m}$ resolution (Leica Vector GIS, Leica AG, Heerbrugg, Switzerland). Paddock size was measured using the walking wheel, and all information was drawn to scale on millimeter-ruled paper and copied into WebShade. The program produces a shade projection per solid object based on location, date, time of day, and tree characteristics (height, width, shape). This enables calculation of the total amount of shade per paddock at different times of day and how far shade will be cast from a solid object. Shade for all observation paddocks was projected at 1000, 1200, and 1400 $\mathrm{h}$, and the average was calculated. The projected shade at $1200 \mathrm{~h}$ around solid objects was marked using ProEarth plastic pin marker flags (Prospectors, Orange, NSW, Australia) to facilitate observations when shade was not visible because of cloud cover.

\section{Behavioral and Physiological Measurements}

Behavioral observations were carried out between 1000 and $1530 \mathrm{~h}$ (between morning and afternoon milking); this time period was chosen as the range that could be consistently measured on all farms and captures the peak of solar radiation (around noon) in this region (for description of diurnal variation in this measure in Waikato, see Tucker et al., 2008). Fifteen cows per herd were randomly chosen as focal animals and identified using tail paint (Tell-tail paint, FIL NZ Ltd., Mount Maunganui, New Zealand). For these animals, time budgets for lying, standing, and grazing were estimated using 20-min instantaneous scan sampling (Martin and Bateson, 1993); cattle had to be performing 1 of these 3 behaviors and the percentage of time engaged in each of these 3 accounted for all time observed. Cows were considered lying if their flank was in contact with the ground and standing if not. Cows were considered eating if feed (grass or supplements) was being ingested or could be seen in the mouth. Rumination was defined as chewing movements without feed in the mouth, regurgitation of feed, or both. Shade use and proximity to the water trough were also recorded with the same sampling interval. Shade use was measured in 2 ways 
to account for the movement of shade throughout the day. We recorded if at least one hoof was within the shade area marked with flags (shade cast at $1200 \mathrm{~h}$ ). Second, we recorded if at least one hoof was within the visible shadow. This second measurement was only taken when the outline of the shadow was clearly defined. Both measures were used because recording only the latter might underestimate shade use (shade was visible in $48 \%$ of observations) and using only the flag measure would also underestimate shade use, as the shade moved outside the flag area at certain times. For statistical analysis, measures of shade use were combined and an animal was considered using shade if it had at least one hoof in either the marked area or visible shade. An area around each water trough (10-m radius from the trough) was marked using the same type of flags as were used to mark the shade. Proximity to water was defined as having at least one hoof within the marked circle. Multiple individuals carried out these observations and interobserver reliability for the above mentioned behaviors ranged between 95 and $99 \%$ agreement.

In addition to the focal instantaneous scan observations, we recorded the number of cows within the herd using the shade (defined as having at least one hoof within the shade area marked with flags) and number of cows near the water trough every $30 \mathrm{~min}$ (expressed as percentage of the herd). The same person also walked slowly through the paddock in a "W" pattern every 30 min and recorded the number of cows with a panting score of $\geq 2$ (Table 1 ). A cutoff score of 2 (drool is present) was used to enable relatively rapid scanning of all animals. Multiple people carried out these observations and the reliability among observers for counts of panting score, near the water trough, and in the flagged shade area was $0.92 \pm 0.141,1.0 \pm 0.001$, and $1.0 \pm$ 0.005 , respectively, as measured by correlation $( \pm \mathrm{SD})$.

The panting score of each focal cow was recorded every $20 \mathrm{~min}$ (Table 1 ). In addition, the respiration rate of each focal cow was recorded once per hour by timing 10 breaths using a stop watch. Respiration rate was then recalculated as breaths per minute (bpm) to facilitate comparisons with other studies. Multiple observers recorded respiration rate, and the reliability between observers was $0.97 \pm 0.013$ using correlation $( \pm \mathrm{SD})$.

\section{Environmental Measurements}

Air temperature and relative humidity (HMP45A humidity and temperature sensor, Vaisala, Helsinki, Finland), wind speed (\#40 Hall effect anemometer, NRG Systems, Hinesburg, VT), rainfall (tipping spoon rain gauge, Pronamic Silkeborg, Denmark), solar radiation (Li-Cor Li200x Pyranometer, Campbell Scientific Inc., Logan, UT), and black globe temperature (BGT, CSI 107 temperature sensor in black ball, Campbell Scientific Inc.) were recorded at 10-min intervals between 1000 and $1530 \mathrm{~h}$ with a data logger (CR10X, Campbell Scientific Inc.) on a weather station located outside the observation paddock. The microclimate (temperature, humidity, BGT) in the shade (the logger was hung in a tree out of reach from the cows) was measured with Hobo Pro Dataloggers (Onset Computer Corp., Bourne, MA). Ideally, all aspects of weather would have been quantified in this area, as natural forms of shade vary in terms of how they affect both wind speed and solar radiation (e.g., reviewed by Gregory, 1995). These measures were excluded in the current work because of the logistical challenges associated with placing a full weather station under the shade and in proximity to cows.

The temperature-humidity index (THI; Igono et al., 1992) and heat-load index (HLI; Gaughan et al., 2008) were calculated as follows:

$$
\begin{gathered}
\mathrm{THI}=(1.8 \times \mathrm{T}+32)-[(0.55-0.0055 \times \mathrm{RH}) \\
\times(1.8 \times \mathrm{T}-26)] \\
\mathrm{HLI} \text { if } \mathrm{BGT}>25=8.62+(0.38 \times \mathrm{RH}) \\
+(1.55 \times \mathrm{BGT})+\exp (-\mathrm{WS}+2.4)-0.5 \times \mathrm{WS}, \\
\mathrm{HLI} \text { if } \mathrm{BGT} \leq 25=10.66+(0.28 \times \mathrm{RH}) \\
+(1.3 \times \mathrm{BGT})-\mathrm{WS},
\end{gathered}
$$

\begin{tabular}{|c|c|}
\hline Panting score & Breathing condition \\
\hline 0 & No panting. \\
\hline 1 & Slight panting, mouth closed, no drool, easy to see chest movement. \\
\hline 2 & Fast panting, drool present, no open mouth. \\
\hline 2.5 & As for 2 but occasional open-mouth panting, tongue not extended. \\
\hline 3 & Open mouth and excessive drooling, neck extended, head held up. \\
\hline 3.5 & As for 3 but with the tongue out slightly and occasionally fully extended for short periods. \\
\hline 4 & Open mouth with tongue fully extended for prolonged periods with excessive drooling, neck extended, and head held up. \\
\hline 4.5 & As for 4 but head held down and cattle breathing from the flank. Drooling may cease. \\
\hline
\end{tabular}

Table 1. Panting scores and breathing condition used as a measure of heat load in cattle (Gaughan et al., 2008) 
where $\mathrm{T}=$ air temperature $\left({ }^{\circ} \mathrm{C}\right), \mathrm{RH}=$ relative humidity $(\%), \mathrm{BGT}=$ black globe temperature $\left({ }^{\circ} \mathrm{C}\right)$, and WS $=$ wind $\operatorname{speed}(\mathrm{m} / \mathrm{s})$.

\section{Statistical Analysis}

First, an ANOVA was used to facilitate comparisons of animals with access to shade with those that had none. Second, the relationship between the response variables and the amount of shade available (daily mean) was explored using REML with farm as a random term and allowing each year to have a different intercept (to obtain a pooled within year relationship). Values were averaged within a herd and day. Data from paddocks where no shade was available were only excluded for response variables measuring shade use. This model was also extended to include air temperature, THI, or HLI as a fixed effect. All statistical analyses were conducted using GenStat, version 13.2 (VSN International, Hemel Hempstead, UK).

\section{RESULTS}

\section{Environmental Conditions}

A summary of daily (1000 to $1530 \mathrm{~h}$ ) environmental recordings during the experiment and calculated THI and HLI are presented in Table 2.

\section{Effects of Shade Versus No Shade}

The behavior and respiration rate for cows with and without access to shade are presented in Table 3. All animals spent the majority of the observation period standing (which also included walking) and eating. Cows with access to shade spent on average $31 \%$ of their time using this resource (range: $0.4-74 \%$ of their time). Cows with no shade spent $4 \%$ more time lying than cows with shade (Table 3). A larger proportion of the herd had panting scores $\geq 2$ when no shade was available ( 6 vs. $2 \%$ of the herd; Table 3 ). In addition, respiration rates tended to be higher by $8 \mathrm{bpm}$ in cows without shade (Table 3 ).

\section{Effects of Amount of Shade}

All cows in a herd were physically able to use the shade simultaneously when the shade amount exceeded $2 \mathrm{~m}^{2} /$ cow; however, a greater proportion of the herd could use the shade at the same time as the amount of shade increased. The maximum proportion of the herd that were observed using the shade simultaneously at least once increased by $3.1 \%$ for every $1-\mathrm{m}^{2}$ increase in shade size $(P=0.042, \mathrm{SE}=1.51$; Figure 1$)$. All animals in a herd were rarely seen in the shade at the same time, on only 7 occasions out of a total of 309 scans: 5 times when the cows had access to $2.1 \mathrm{~m}^{2}$ shade/ cow and once each when the cows had access to $8.1 \mathrm{~m}^{2}$ and $8.8 \mathrm{~m}^{2}$ shade/cow (Figure 2). The amount of shade influenced the proportion of the herd with panting scores $\geq 2$; for every $1-\mathrm{m}^{2}$ increase in shade, $0.3 \%$ fewer cows had a panting score $\geq 2(P=0.033, \mathrm{SE}=0.12 \%$; Figure 1). Panting scores $>3.5$ (open mouth, excessive drooling, neck extended, head held up and with tongue fully extended for short periods) were never observed.

We observed no significant relationships between any other behavioral or physiological variables and the amount of shade available $(P \geq 0.108)$. Inclusion of weather variables in the model sometimes gave a significant improvement to model fit but generally had little effect on the relationship between response variables and amount of shade; hence, we have not included the results of these analyses.

\section{DISCUSSION}

When provided with shade on commercial dairy farms, cattle readily used this resource. Cows with shade spent less time lying and were less likely to pant than cows with no shade. The maximum proportion of the herd using shade increased, and the proportion of cows with high panting scores decreased as more shade was provided.

Table 2. Summary of daily (1000 to $1530 \mathrm{~h}$ ) environmental conditions on observation days

\begin{tabular}{|c|c|c|c|c|}
\hline \multirow[b]{2}{*}{ Item $^{1}$} & \multicolumn{2}{|c|}{ In sun } & \multicolumn{2}{|c|}{ In shade } \\
\hline & Mean & Range & Mean & Range \\
\hline Temperature $\left({ }^{\circ} \mathrm{C}\right)$ & 23 & $21-25$ & 23 & $21-26$ \\
\hline Humidity (\%) & 59 & $48-75$ & 61 & $53-75$ \\
\hline Solar radiation $\left(\mathrm{W} / \mathrm{m}^{2}\right)$ & 597 & $282-806$ & - & - \\
\hline Wind speed $(\mathrm{m} / \mathrm{s})$ & 4 & $1-7$ & - & - \\
\hline $\mathrm{BGT}\left({ }^{\circ} \mathrm{C}\right)$ & 31 & $26-35$ & 25 & $22-30$ \\
\hline THI & 70 & $67-72$ & 70 & $66-75$ \\
\hline HLI & 81 & $70-91$ & - & - \\
\hline
\end{tabular}

${ }^{1} \mathrm{BGT}=$ black globe temperature; $\mathrm{THI}=$ temperature-humidity index; HLI = heat-load index. 
Table 3. Behavior (between 1000 and $1530 \mathrm{~h}$ ), panting score, and respiration rate in dairy cattle $(\mathrm{n}=8$ herds) that had access to shade $\left(\mathrm{n}=31\right.$ paddocks, range: 0.9 to $15.6 \mathrm{~m}^{2} /$ cow $)$ or no shade $(\mathrm{n}=11$ paddocks $)$ on pasture

\begin{tabular}{|c|c|c|c|c|}
\hline \multirow[b]{2}{*}{ Item } & \multicolumn{2}{|c|}{ Mean } & \multirow[b]{2}{*}{$\mathrm{SED}^{1}$} & \multirow[b]{2}{*}{$P$-value } \\
\hline & Shade & No shade & & \\
\hline In shade ( $\%$ of herd $)$ & 27 & - & - & - \\
\hline Near water ( $\%$ of herd) & 5 & 6 & 1.7 & 0.757 \\
\hline Panting score $\geq 2$ ( $\%$ of herd $)$ & 2 & 6 & 1.2 & 0.008 \\
\hline In shade ${ }^{2}(\%$ of time) & 31 & - & - & - \\
\hline Near water ${ }^{2}(\%$ of time) & 6 & 6 & 2.0 & 0.911 \\
\hline Eating $^{2}(\%$ of time) & 38 & 40 & 4.7 & 0.767 \\
\hline Ruminating $^{2}$ ( $\%$ of time) & 24 & 24 & 4.2 & 0.932 \\
\hline Standing $^{2}(\%$ of time $)$ & 59 & 53 & 4.5 & 0.228 \\
\hline Lying $^{2}$ ( $\%$ of time) & 3 & 7 & 1.9 & 0.033 \\
\hline Panting score ${ }^{2}$ (mean) & 1 & 1 & 8.6 & 0.160 \\
\hline 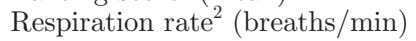 & 65 & 73 & 4.7 & 0.097 \\
\hline
\end{tabular}

${ }^{1} \mathrm{SED}=\mathrm{SE}$ of the difference.

${ }^{2}$ Based on values from 15 focal animals within the herd.

The present study is, to our knowledge, the first study to investigate the effects of the amount of shade on the behavior and physiology of cows on commercial pasture-based dairy farms. Irrespective of the shade amount provided on the different farms, cows used the shade, on average, $1.7 \mathrm{~h} / 5.5 \mathrm{~h}$ (maximum shade use was $4.1 \mathrm{~h} / 5.5 \mathrm{~h}$ ). These findings agree with controlled studies in pasture-based systems in the same region with similar breeds (Tucker et al., 2008; Schütz et al., 2009, 2010) and demonstrates that cows will readily use shade in summer when given access to it. For every $1-\mathrm{m}^{2}$ increase in shade, $3.1 \%$ more of the herd could use the shade. Similarly, pastured beef cattle are more likely to use shade when more is provided (quantity estimated as percentage pasture shaded; Rosselle et al., 2013). In the current work, all cows in a herd were physically able to use the shade simultaneously when the amount was $2 \mathrm{~m}^{2}$ shade/cow; however, on this occasion, aggressive behavior and crowding was common (personal observation). Others have suggested, but not empirically evaluated, the idea that crowding may limit radiant heat loss among cattle (Berman and Horovitz, 2012). Simultaneous shade use increases when more shade is provided (here, and in Schütz et al., 2010), but more research is needed to determine what type of sampling is needed to accurately assess how often all cows in a group share shade and how such rare phenomena should be interpreted. For example, in the present study, $100 \%$ of the animals in a herd were observed using shade only on 7 occasions, out of a total of 309 scans; even a high proportion of the herd using shade at the same time was relatively uncommon. Indeed, even less strict parameters (e.g., $90 \%$ or more of herd using shade at the same time) were relatively rare. Recommendations about the amount of a resource can be based on the animals' ability to use it at the same time (e.g., feedbunk space; National Dairy Farm Program, 2013); thus, this aspect of shade use deserves attention in future research.

As more shade was provided, fewer cows had high panting scores $(\geq 2)$. These results agree with previous findings that providing a large amount of shade more effectively reduced heat load compared with providing less shade. For example, cows with access to $9.6 \mathrm{~m}^{2}$ shade/cow had lower respiration rates and showed less aggressive behavior in the shade than cows with 2.4 $\mathrm{m}^{2}$ shade/cow (Schütz et al., 2010). Furthermore, panting scores of beef cattle in Australia were higher when $2.0 \mathrm{~m}^{2}$ /animal of shade was provided, and shade use was lower, compared with that of cattle with access to 3.3 and $4.7 \mathrm{~m}^{2}$ shade/animal (Sullivan et al., 2011). Providing cows with more shade is likely beneficial in terms of reducing competition for the resource as well as enabling more space between animals, thereby increasing the air flow around individuals.

Grazing and feed intake are reduced by heat, but the effect of mitigation strategies is less clear. Shade provision increases feed intake in feedlot beef cattle (Mitlöhner et al., 2001; Gaughan et al., 2010; Blaine and Nsahlai, 2011), but less is known about how access to shade influences grazing behavior on pasture. Cattle with access to $3.6 \mathrm{~m}^{2}$ shade/cow spent less time grazing during daytime compared with cows with no shade, but no differences were observed over $24 \mathrm{~h}$ (Kendall et al., 2006), whereas access to at least $2.4 \mathrm{~m}^{2}$ shade/cow in summer did not change daytime grazing behavior in groups of cattle (Schütz et al., 2010) or over $24 \mathrm{~h}$ (Fisher et al., 2008; Tucker et al., 2008). However, the cows in those studies were well fed and did not have to spend a large proportion of the day grazing to obtain daily intake. We previously showed that daytime grazing behavior did not differ in cattle that had access 
A)

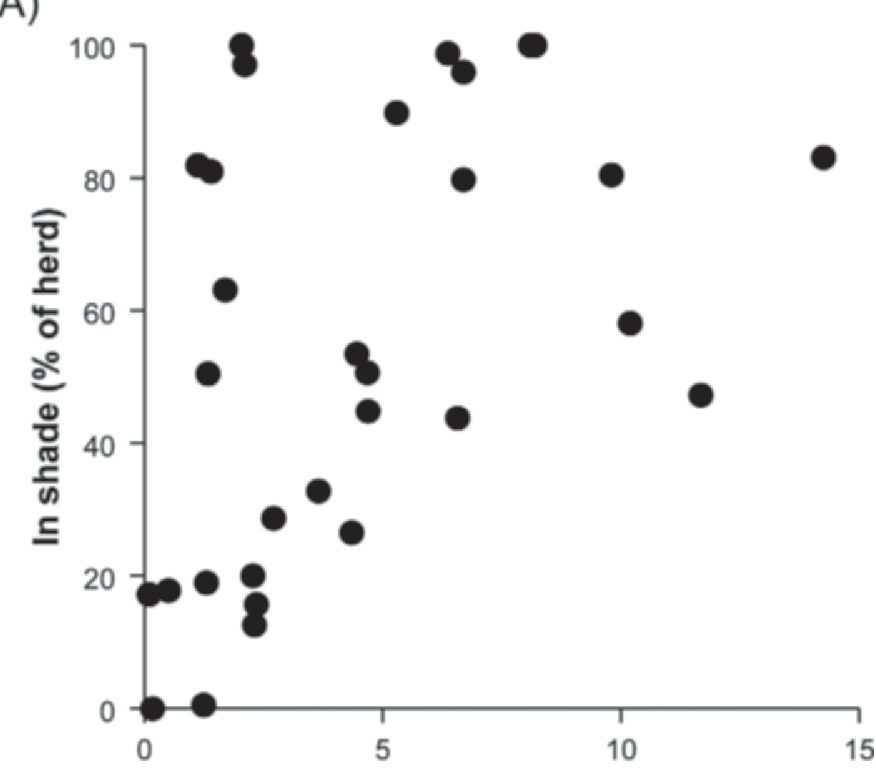

B)

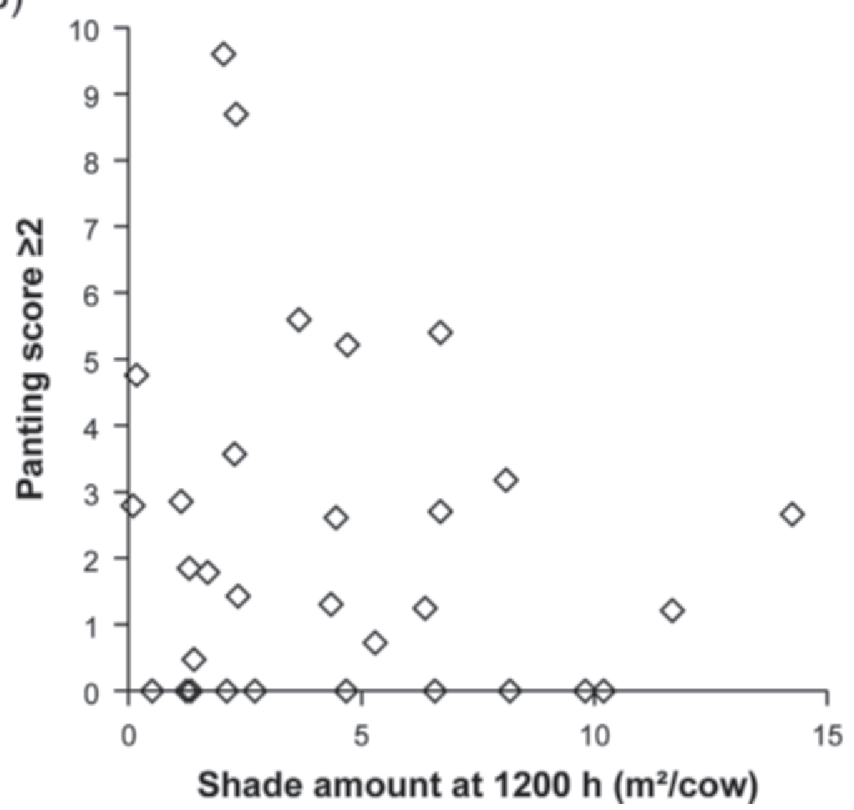

Figure 1. Simultaneous shade use (A: maximum percentage of the herd in shade, $\mathrm{n}=8$ herds observed on multiple days) and panting score (B: maximum percentage of the herd with panting scores $\geq 2$ ) by pastured dairy cattle in relation to the amount of shade provided. Each symbol represents 1 herd on 1 observation day.

to either 2.4 or $9.6 \mathrm{~m}^{2}$ shade/cow, despite cows with the larger shade using this resource more than twice as much as cows with the smaller allotment (Schütz et al., 2010). In contrast, grazing was positively correlated with shade use in steers (Bennett et al., 1984-1985) and grazing has also been documented when large tracks of shade and forage are provided together in beef systems

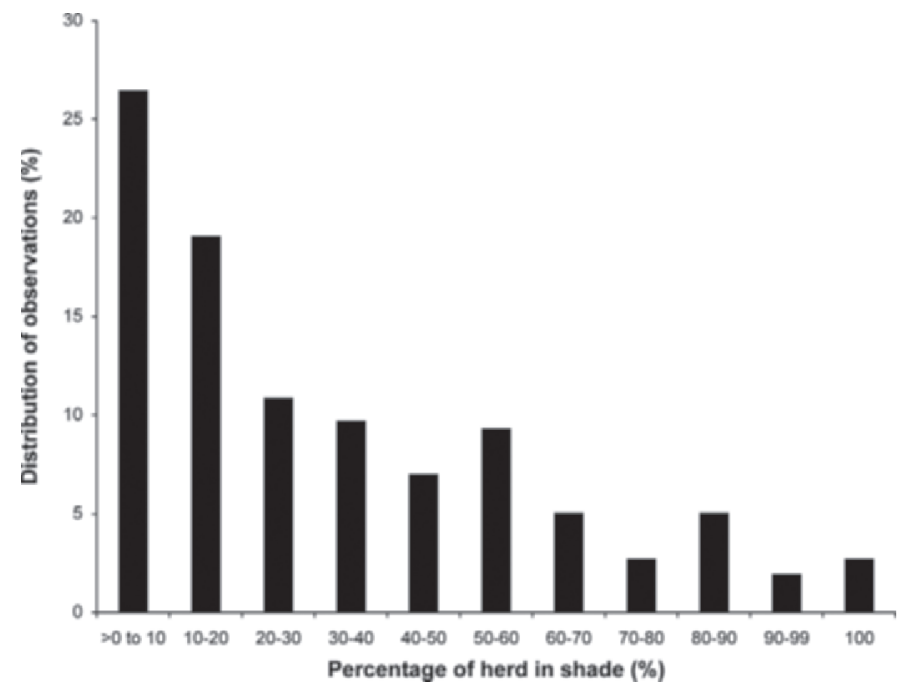

Figure 2. Frequency distribution of scans with a given percentage of the herd in shade ( $\mathrm{n}=8$ herds observed on multiple days, every 30 min between 1000 and $1530 \mathrm{~h}$ ).

(Karki and Goodman, 2010). In the current study, we found no effect of shade amount on grazing and speculate that differences in results between experiments may be due, in part, to environmental conditions and the amount or type of feed available.

Overall, cows in general spent very little time lying at this time of day and these results may be due to a combination of the nutritional need to feed and or as a response to heat load, as seen in many other experiments (e.g., Mader et al., 1997; Tucker et al., 2008; Schütz et al., 2010). Surprisingly, cows with no shade spent more time lying than cows with shade, and the reason for this and biological importance of this difference is unclear. It is possible that on some days, cows with some shade preferred to stand in the shade, whereas cows without this resource instead spent more time lying, particularly on cooler days.

The provision of shade also tended to reduce respiration rate (by, on average, $8 \mathrm{bpm}$ ). These differences are within the range of reduction reported by others comparing shaded and unshaded cattle; for example, 6 to 11 bpm (Schütz et al., 2010), 13 bpm (Mitlöhner et al., 2001), and 2 to 11 bpm (Brown-Brandl et al., 2005). However, we observed no differences in time spent near the water trough, a behavioral change seen consistently in other studies (Mader et al., 1997; Widowski, 2001; Schütz et al., 2010). Perhaps the moderate weather conditions or space limitations around the water trough of the current study explain these differences.

Indeed, the effect of weather was difficult to quantify in this experiment. The inclusion of weather variables in the model only slightly changed the prediction for the effect of shade size on behavior and physiology. 
This may well be due to the narrow range of weather conditions encountered in the observation period (21 to $25^{\circ} \mathrm{C}$ range for average temperature).

\section{CONCLUSIONS}

When provided with shade on commercial dairy farms, dairy cattle readily used this resource under the conditions of this study. Cows with access to shade had lower panting scores and respiration rates than cows with no shade. The proportion of the herd using shade increased and the proportion of cows with high panting scores decreased when more shade was provided. The results demonstrate that providing more shade allows a higher proportion of animals to use this resource and reduces respiratory signs of heat load.

\section{ACKNOWLEDGMENTS}

We are grateful to all farmers who participated in the study and gave us access to their farms. We are also grateful to Tyler Elkington, Lauri Garrick, Gemma Lowe, and Lauren Werrey (University of Waikato, New Zealand) and the staff at AgResearch Ltd. (New Zealand): Suzanne Dowling, Frankie Huddart, Gemma Worth, and Andrea Rogers. The study was funded by the Ministry of Business, Innovation and Employment (Wellington, New Zealand).

\section{REFERENCES}

Bennett, I. L., V. A. Finch, and C. R. Holmes. 1984-1985. Time spent in shade and its relationship with physiological factors of thermoregulation in three breeds of cattle. Appl. Anim. Behav. Sci. 13:227-236.

Berman, A., and T. Horovitz. 2012. Radiant heat loss, an unexploited path or heat stress reduction in shaded cattle. J. Dairy Sci. 95:3021-3031.

Blaine, K. L., and I. V. Nsahlai. 2011. The effects of shade on performance, carcass classes and behaviour of heat-stressed feedlot cattle at the finisher phase. Trop. Anim. Health Prod. 43:609-615.

Brown-Brandl, T. M., R. A. Eigenberg, J. A. Nienaber, and G. L. Hahn. 2005. Dynamic response indicators of heat stress in shaded and non-shaded feedlot cattle. Part 1: Analyses of indicators. Biosystems Eng. 90:451-462.

Buffington, D. E., R. J. Collier, and G. H. Canton. 1983. Shade management systems to reduce heat stress for dairy cows in hot, humid climates. Trans. ASAE 26:1798-1802.

Collier, R. J., G. E. Dahl, and M. J. VanBaale. 2006. Major advances associated with environmental effects on dairy cattle. J. Dairy Sci. 89:1244-1253.

National Dairy Farm Program. 2013. Farmers Assuring Responsible Management (FARM) Animal Care Reference Manual. Accessed Mar. 24, 2014. http://www.nationaldairyfarm.com/sites/default/ files/2013/FARM_manual_2013_WEB.pdf.

Fisher, A. D., N. Roberts, S. J. Bluett, G. A. Verkerk, and L. R. Matthews. 2008. Effects of shade provision on the behaviour, body temperature and milk production of grazing dairy cows during a New Zealand summer. N.Z. J. Agric. Res. 51:99-105.

Gaughan, J. B., S. Bonner, I. Loxton, T. L. Mader, A. Lisle, and R. Lawrence. 2010. Effect of shade on body temperature and performance of feedlot steers. J. Anim. Sci. 88:4056-4067.
Gaughan, J. B., T. L. Mader, S. M. Holt, and A. Lisle. 2008. A new heat load index for feedlot cattle. J. Anim. Sci. 86:226-234.

Gregory, N. G. 1995. The role of shelterbelts in protecting livestock: A review. N.Z. J. Agric. Res. 38:423-450.

Hahn, G. L. 1999. Dynamic responses of cattle to thermal heat loads. J. Anim. Sci. 77:10-20.

Igono, M. O., G. Bjotvedt, and H. T. Sanford-Crane. 1992. Environmental profile and critical temperature effects on milk production of Holstein cows in desert climate. Int. J. Biometeorol. 36:77-87.

Karki, U., and M. S. Goodman. 2010. Cattle distribution and behavior in southern-pine silvopasture versus open-pasture. Agrofor. Syst. 78:159-168.

Kendall, P. E., P. P. Nielsen, J. R. Webster, G. A. Verkerk, R. P. Littlejohn, and L. R. Matthews. 2006. The effects of providing shade to lactating dairy cows in a temperate climate. Livest. Sci. 103:148-157.

Kendall, P. E., G. A. Verkerk, J. R. Webster, and C. B. Tucker. 2007. Sprinklers and shade cool cows and reduce insect-avoidance behavior in pasture-based dairy systems. J. Dairy Sci. 90:3671-3680.

Legrand, A., K. E. Schütz, and C. B. Tucker. 2011. Using water to cool cattle: Behavioral and physiological changes associated with voluntary use of cow showers. J. Dairy Sci. 94:3376-3386.

Mader, T. L., L. R. Fell, and M. J. McPhee. 1997. Behavior response of non-Brahman cattle to shade in commercial feedlots. Livest. Environ. 5:795-802.

Martin, P., and P. Bateson. 1993. Measuring Behavior: An Introductory Guide. 2nd ed. Cambridge University Press, Cambridge, UK.

Mitlöhner, F. M., J. L. Morrow, J. W. Dailey, S. C. Wilson, M. L. Galyean, M. F. Miller, and J. J. McGlone. 2001. Shade and water misting effects on behavior, physiology, performance, and carcass traits of heat-stressed feedlot cattle. J. Anim. Sci. 79:2327-2335.

Ominski, K. H., A. D. Kennedy, K. M. Wittenberg, and S. A. Moshtaghi Nia. 2002. Physiological and production responses to feeding schedule in lactating dairy cows exposed to short-term, moderate heat stress. J. Dairy Sci. 85:730-737.

Rosselle, L., L. Permentier, G. Verbeke, B. Driessen, and R. Geers. 2013. Interactions between climatological variables and sheltering behavior of pastoral beef cattle during sunny weather in a temperate climate. J. Anim. Sci. 91:943-949.

Schütz, K. E., A. R. Rogers, N. R. Cox, and C. B. Tucker. 2009. Dairy cows prefer shade that offers greater protection against solar radiation in summer: Shade use, behaviour, and body temperature. Appl. Anim. Behav. Sci. 116:28-34.

Schütz, K. E., A. R. Rogers, N. R. Cox, J. R. Webster, and C. B. Tucker. 2011. Dairy cattle prefer shade over sprinklers: Effects on behavior and physiology. J. Dairy Sci. 94:273-283.

Schütz, K. E., A. R. Rogers, Y. A. Poulouin, N. R. Cox, and C. B. Tucker. 2010. The amount of shade influences the behavior and physiology of dairy cattle. J. Dairy Sci. 93:125-133.

Stull, C. L., L. L. McV. Messam, C. A. Collar, N. G. Peterson, A. R. Castillo, B. A. Reed, K. L. Andersen, and W. R. VerBoort. 2008. Precipitation and temperature effects on mortality and lactation parameters of dairy cattle in California. J. Dairy Sci. 91:45794591.

Sullivan, M. L., A. J. Cawdell-Smith, T. L. Mader, and J. B. Gaughan. 2011. Effect of shade area on performance and welfare of short-fed feedlot cattle. J. Anim. Sci. 89:2911-2925.

Tucker, C. B., A. R. Rogers, and K. E. Schütz. 2008. Effect of solar radiation on dairy cattle behaviour, use of shade and body temperature in a pasture-based system. Appl. Anim. Behav. Sci. 109:141-154.

Wheelock, J. B., R. P. Rhoads, M. J. VanBaale, S. R. Sanders, and L. H. Baumgard. 2010. Effects of heat stress on energetic metabolism in lactating Holstein cows. J. Dairy Sci. 93:644-655.

Widowski, T. 2001. Shade-seeking behavior of rotationally grazed cows and calves in a moderate climate. Pages 632-639 in Livestock Environment VI: Proc. 6th Int. Symp., Louisville, KY. R. R. Stowell, R. Bucklin, and R. W. Bottcher, ed. ASAE Publ. No. 701P0201. Am. Soc. Agric. Eng., St. Joseph, MI. 